This item was submitted to Loughborough's Research Repository by the author.

Items in Figshare are protected by copyright, with all rights reserved, unless otherwise indicated.

\title{
Rapid prototyping for direct manufacture
}

PLEASE CITE THE PUBLISHED VERSION

PUBLISHER

(c) Emerald Group Publishing Limited (MCB University Press)

LICENCE

CC BY-NC-ND 4.0

REPOSITORY RECORD

Hopkinson, Neil, and Phill M. Dickens. 2019. "Rapid Prototyping for Direct Manufacture". figshare. https://hdl.handle.net/2134/3509. 
This item was submitted to Loughborough's Institutional Repository by the author and is made available under the following Creative Commons Licence conditions.

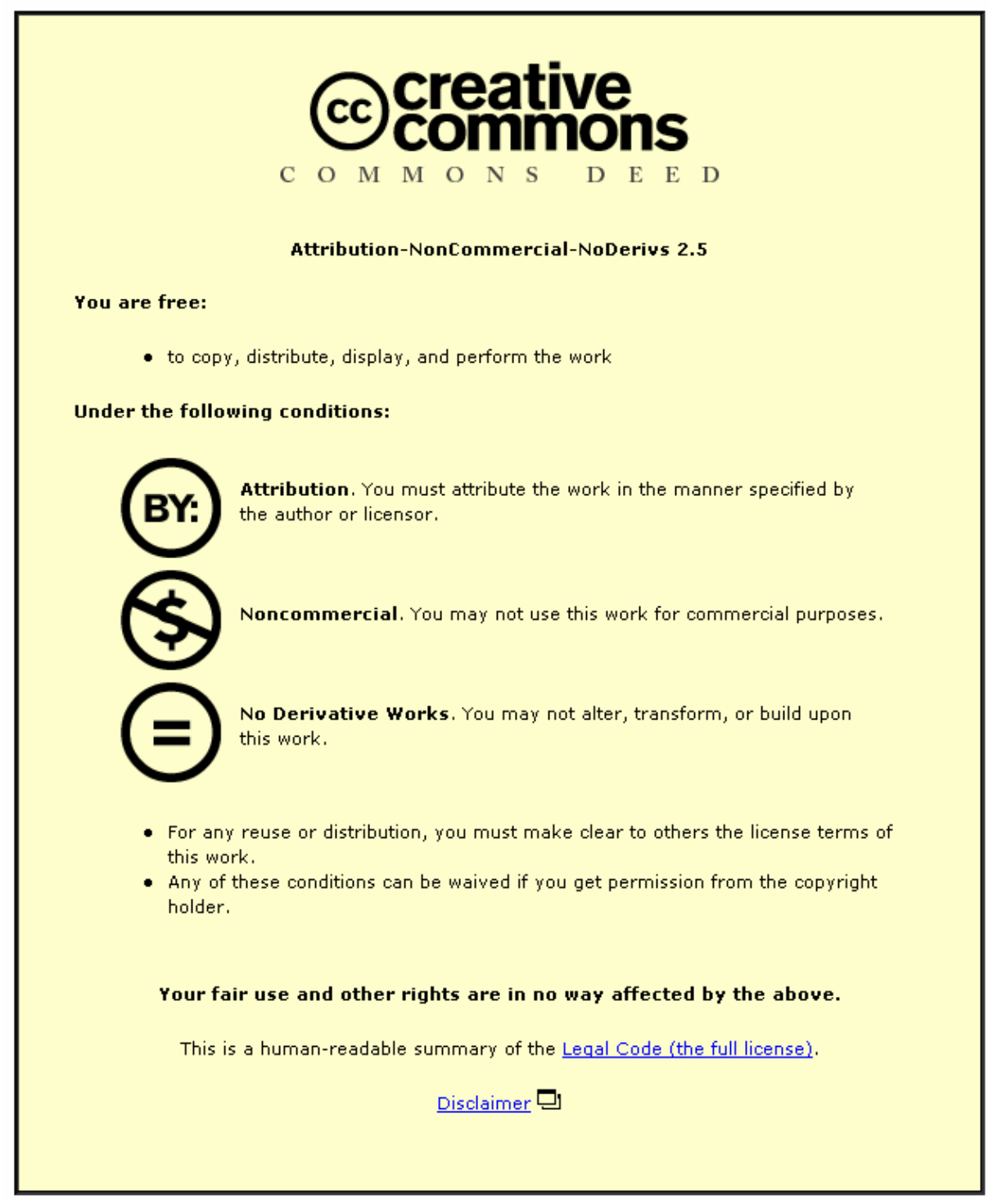

For the full text of this licence, please go to: http://creativecommons.org/licenses/by-nc-nd/2.5/ 


\title{
Rapid Prototyping for Direct Manufacture
}

\author{
Neil Hopkinson and Phill Dickens
}

\section{Abstract}

The paper introduces the concept of using technologies collectively known as Rapid Prototyping (RP) for the manufacture of end use products rather than prototypes and recent examples are presented. Details of a cost analysis performed by De Montfort University and Delphi Automotive Systems (France) are given. The cost analysis was used to investigate the feasibility of using Stereolithography to manufacture parts which are currently made by injection moulding. The findings from the cost analysis are discussed along with opinions generated form an internet based conference held from November 2000 to January 2001. The combination of findings from the cost analysis with expert opinions generated by the internet conference have helped to identify the potential future for Rapid Manufacturing. In particular the issues of material properties, quality control and identification of suitable products are covered.

\section{Introduction}


The idea of using RP machines for the manufacture of products in high or medium volumes initially seems unrealistic as cycle times, materials costs and capital equipment for processes such as injection moulding are generally far lower than those for RP. However an appreciation that zero tool costs, reduced lead times and considerable gains in terms of freedom in product design and production schedules may significantly benefit manufacturing will help to accept the potential benefits to be gained.

\section{Definitions}

The title of this paper contains a clear paradox in the use of the words "prototyping" and “manufacture” so let’s get things clear from the start:

1. Rapid Prototyping refers to a group of commercially available processes which are used to create solid 3D parts from CAD, from this point onwards these processes will be referred to as layer manufacturing techniques (LMTs).

2. Rapid Manufacturing uses LMTs for the direct manufacture of solid 3D products to be used by the end user either as parts of assemblies or as stand-alone products.

\section{Recent examples of Rapid Manufacturing}

Boeing's Rocketdyne propulsion and power section has used Selective Laser Sintering (SLS) to manufacture low volumes of parts such as for the space lab and space shuttles (1). NASA's Jet Propulsion lab has also used SLS to make parts launched into the upper atmosphere (2). Align Technologies use stereolithography (SL) to produce one-off moulds for orthodontic aligners in the thousands (3). While the manufacture of moulds does not fit in with the definition of Rapid Manufacturing, the ability to increase SL throughput threefold by tuning the hardware and software to produce a standard type of geometry (a sort of cell 
manufacturing approach) is of particular interest. A cost analysis performed by De Montfort University and Delphi Automotive Systems (4) comparing injection moulding with SL showed how LMT's may be used for manufacture of parts in the thousands; this is described in more detail in the next section.

\section{Cost Analysis comparing Injection moulding with SL}

Th cost analysis was used to compare the manufacturing cost per part required to produce four different parts by injection moulding (the process the parts had been designed for) and SL. The parts ranged in size from 3.6 - 740 grams and may be seen in Figures 1-4.

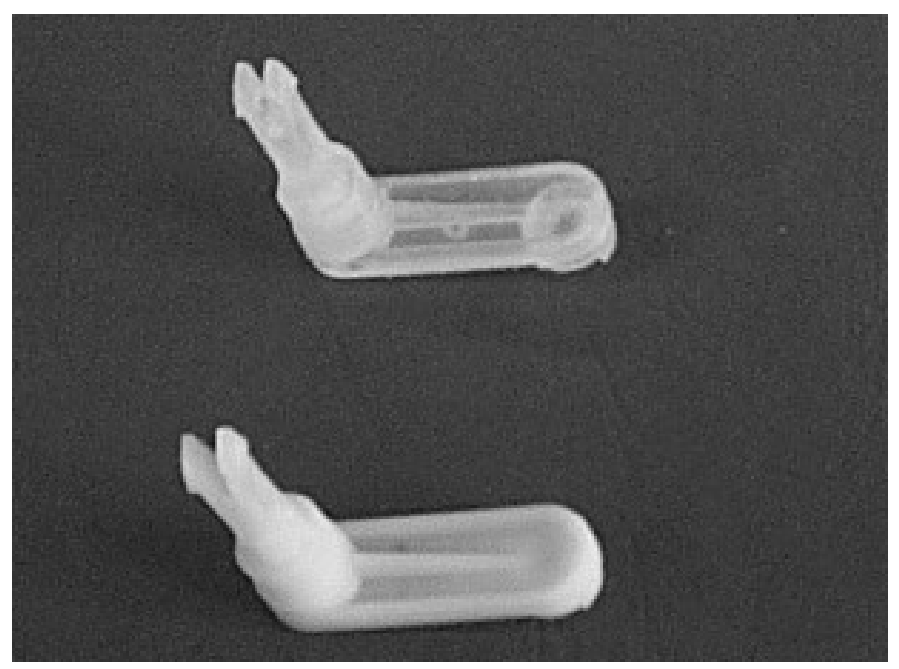

Figure 1. 3.6 Gram parts produced by injection moulding and SL 


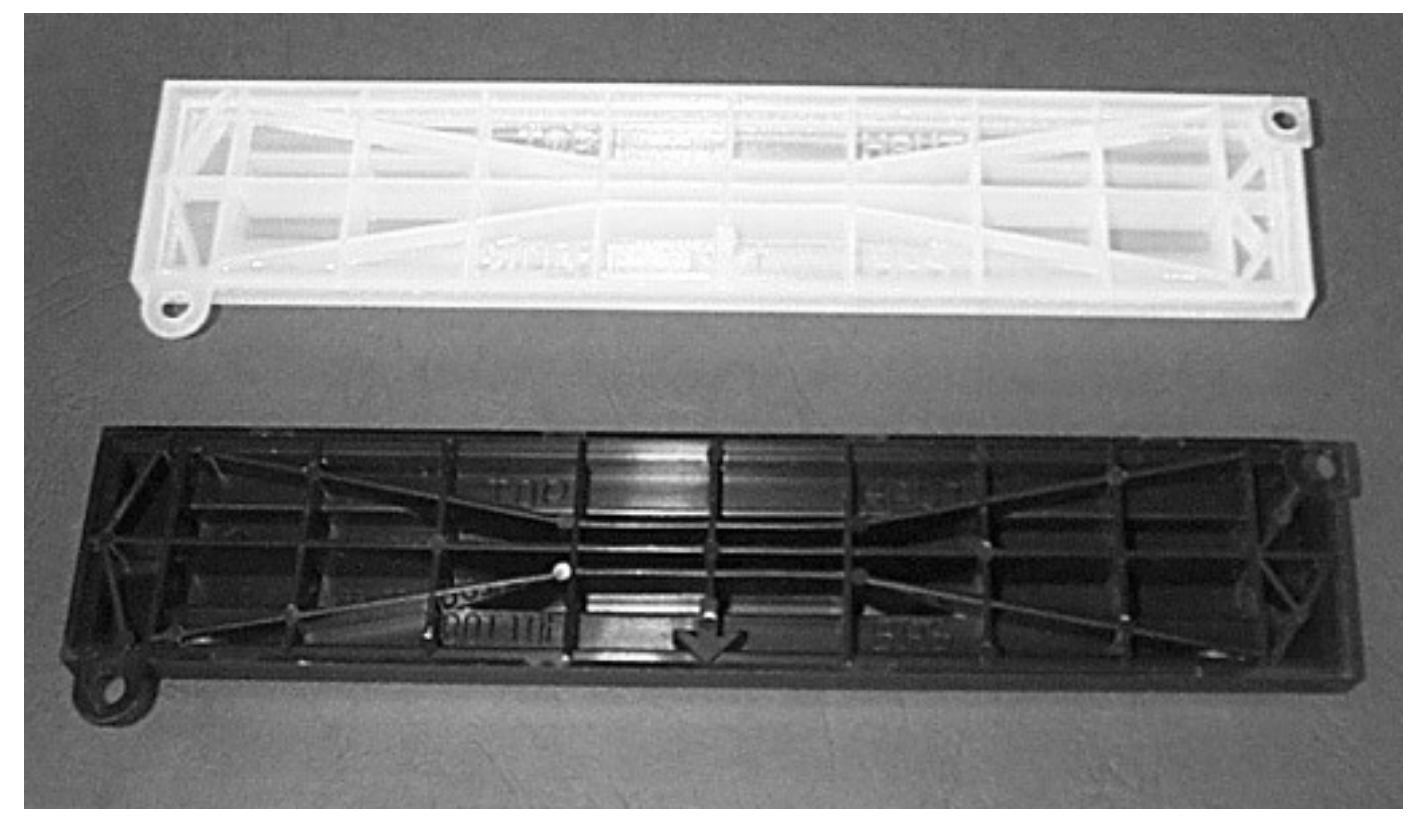

Figure 2. 44 Gram parts produced by injection moulding and SL

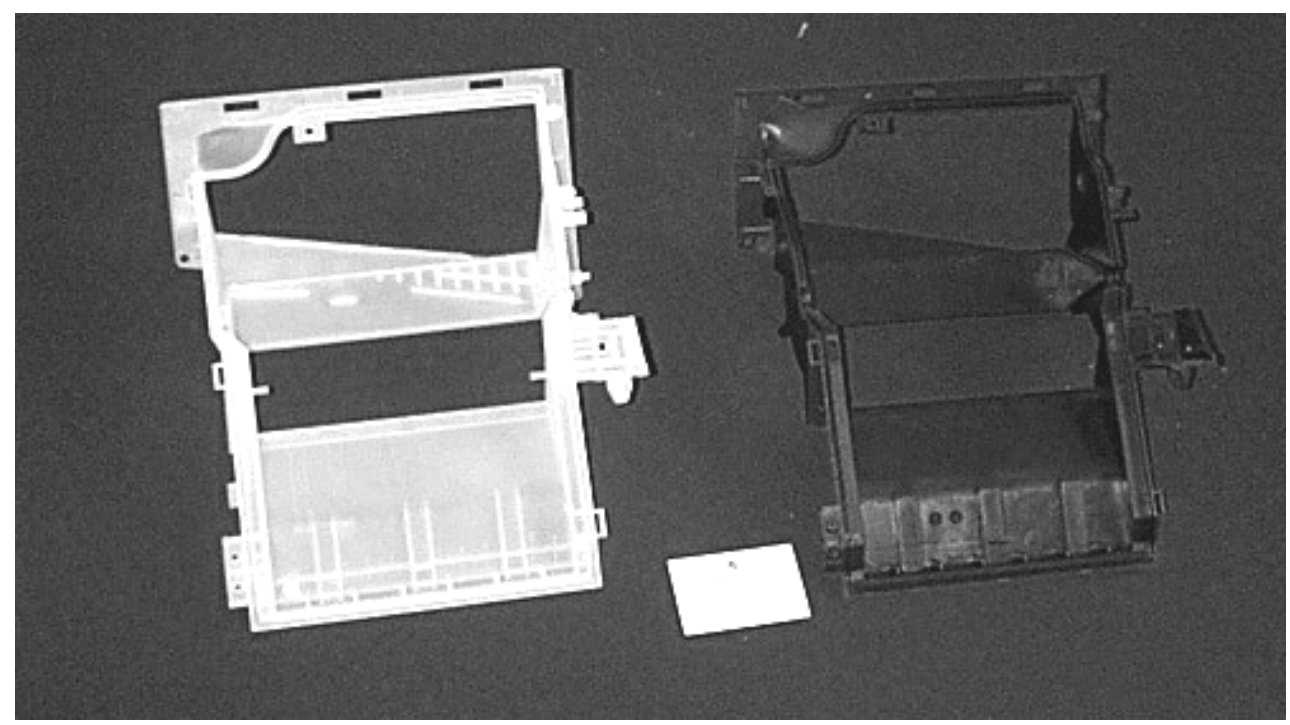

Figure 3. 260 Gram parts produced by injection moulding and SL 


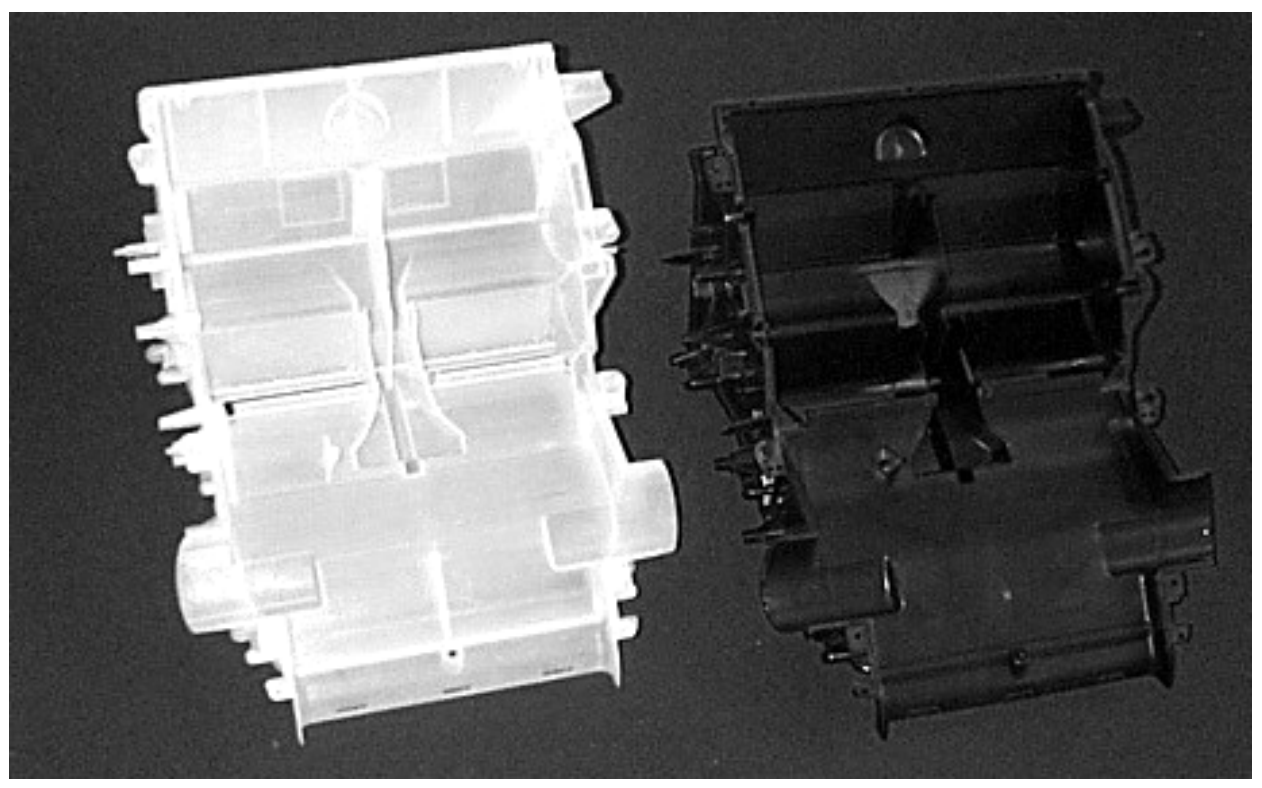

Figure 4. 740 Gram parts produced by injection moulding and SL

\section{Parameters included in the cost analysis}

Table I lists the parameters that were included in the cost analysis for both injection moulding and SL. Costs were based on running equipment for a year with capital equipment subject to a linear eight-year depreciation. For each process the price per part was calculated and this part price was broken down into costs attributed to direct machine cost, indirect machine cost, machine operation cost, material cost and tooling cost. Clearly the tooling cost for SL was zero, as the process requires no tooling.

\section{Issues not included in the cost analysis}

It should be noted that a number of issues were not included in the analysis often because they are difficult to quantify. Some of these issues would further the case for Rapid Manufacturing such as fewer design restrictions leading to more optimal designs. The most important issue which was not considered is the material properties of the parts produced. 
Clearly the material properties and hence functionality of parts are important however, the parts used in the study had been designed to be injection moulded from polypropylene. It is proposed that parts to be made from LMT's will be able to perform the same functions as numerous parts currently made by various moulding processes (this is discussed later).

\begin{tabular}{|c|c|}
\hline Injection Moulding & Stereolithography \\
\hline Direct machine costs & Direct machine costs \\
\hline Machine and ancillary equipment & Machine and ancillary equipment \\
\hline \% usage & \% usage \\
\hline Maintenance & Maintenance \\
\hline Indirect machine costs & Indirect machine costs \\
\hline Machine floor space & Machine floor space \\
\hline Finished parts storage & Finished parts storage \\
\hline Cooling water cost & \\
\hline Machine operation costs & Machine operation costs \\
\hline Machine operator cost & Machine operator cost \\
\hline Machine set up & Operator set up time required to run machine \\
\hline \% operator time required to run machine & Labour to remove supports and excess resin \\
\hline Labour for removing sprue, flash, runners etc & Post curing \\
\hline Machine power consumption & Machine power consumption \\
\hline
\end{tabular}




\begin{tabular}{|l|l|}
\hline Material costs & Material costs \\
\hline Material cost including sprue, runners etc & Material cost including supports \\
\hline Average cost of release agent per part & \\
\hline & \\
\hline Tooling costs & \\
\hline Tool design & \\
\hline Tool purchase & \\
\hline Cost of tool design changes & Production rate per hour \\
\hline Tool maintenance & Maximum production volume per year \\
\hline Tool life (total number of parts) & \\
\hline Tool changeover & \\
\hline Tool storage & \\
\hline Production details & \\
\hline Production volume per tool per year & \\
\hline
\end{tabular}

Table I. Costs used for Injection Moulding and Stereolithography

\section{Results from the cost analysis}

Figure 5 shows graphs of the unit costs for the smallest part according to the total number of parts produced. As would be expected the unit costs for producing low volumes by injection moulding are very high due to the cost of tooling. The unit cost for producing parts by SL are constant irrespective of the total number of parts made. 


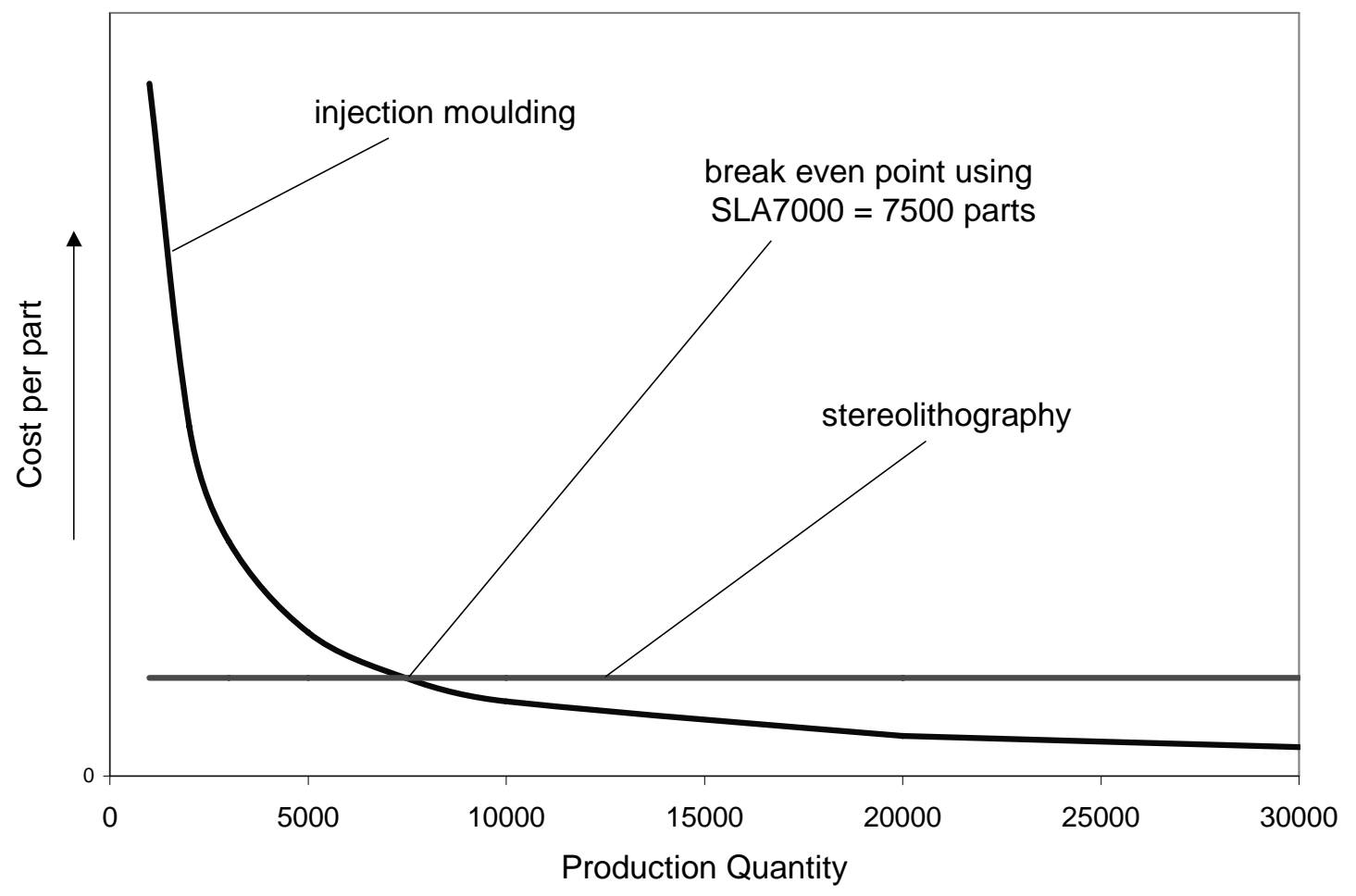

Figure 5. Graphs of unit cost for the 3.6gramme part according to production volume

The break-even point shown in Figure 5 indicates the production volume at which SL becomes a more expensive process than injection moulding is 7500 . The break-even figure of 7500 usually seems very high to experts who work in product development and manufacture - possibly because processes such as SL have only ever really been thought of as suitable for producing one off prototypes. The graph in Figure 5 becomes even more interesting when the experience of Align Technologies, which was mentioned in the Introduction, is accounted for. Align Technologies achieve a threefold increase in production rate when an SL machine is tuned to produce a certain type of part. In this cost analysis a threefold increase in productivity roughly equates to a $66 \%$ decrease in unit production cost 
by SL. Figure 6 shows how a threefold decrease in unit production cost would increase the break-even figure from 7500 to 27000 .

The breakdown of cost per part using SL generally comprised 75\% direct machine costs and 20-25\% materials cost; the labour cost for machine set up and support removal etc was minimal.

Table II shows the break-even figure for all the parts used in the cost analysis. Table II indicates how, other than for small numbers of parts, Rapid Manufacturing appears to be more viable for smaller parts than larger ones. The cost analysis showed that this suitability for smaller parts is due to the lower machine throughput and higher material cost for SL when compared with injection moulding.

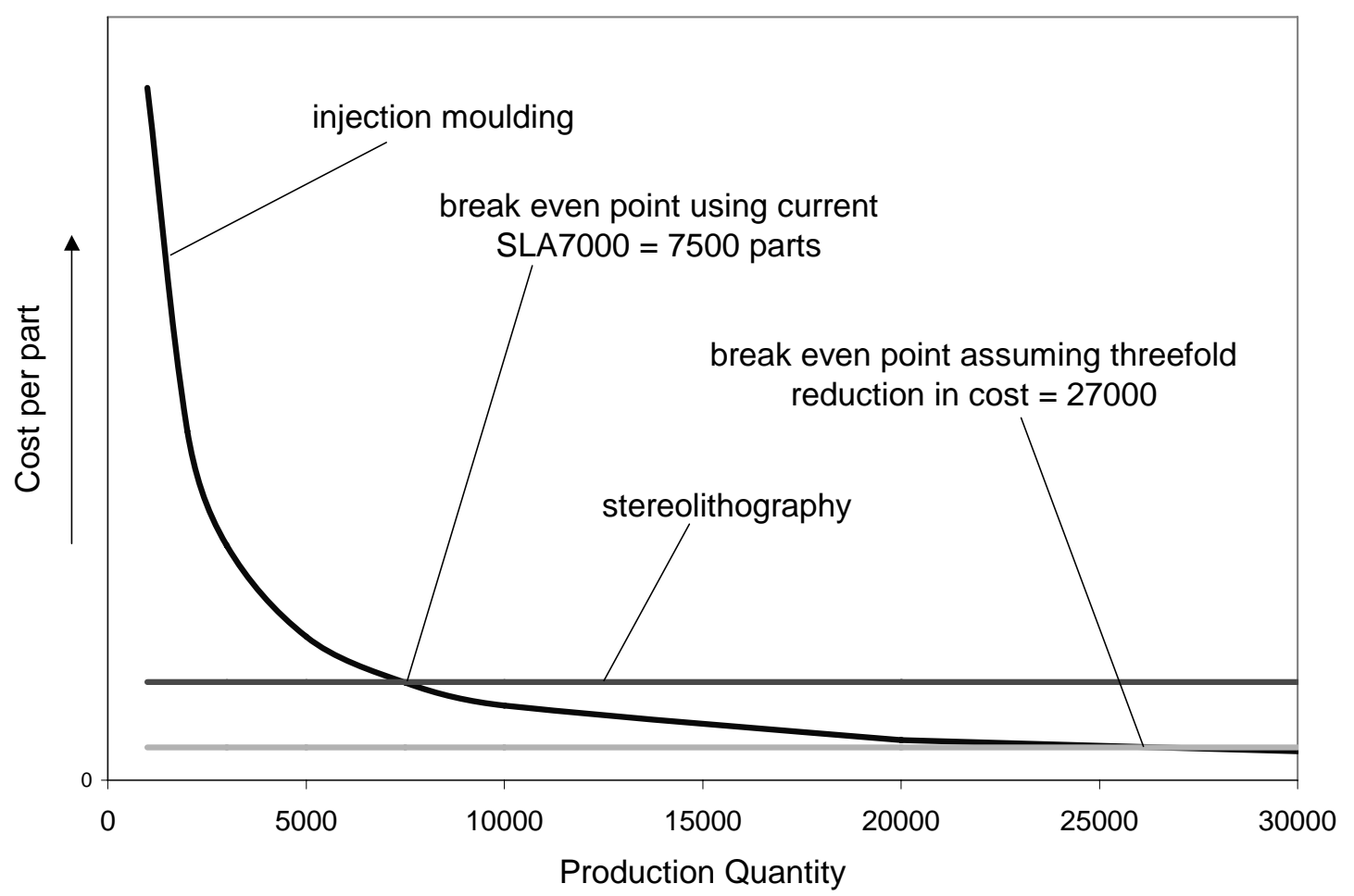

Figure 6. Potential break even Figure for 3.6 gram part with tuned SL machine 


\begin{tabular}{|c|c|c|c|c|}
\hline Part weight (g) & 3.6 & 44 & 260 & 740 \\
\hline Break even figure & 7500 & 875 & $* * 336^{*}$ & 279 \\
\hline
\end{tabular}

Table II. Break-even production figures for the four parts assessed.

\section{Conclusions from the Cost Analysis}

The elimination of tooling helped to significantly reduce unit costs for the parts when using SL as expected. However the break-even figures were higher than expected and may be increased with adjustments to LMT hardware and software. The analysis showed that SL as a manufacturing process is better suited to small parts due to machine speed. The breakdown of costs showed that for SL, the cost per part comprised almost entirely the machine and material costs. Cheaper machines and materials would help to reduce the costs of Rapid Manufacturing thus making their use more financially viable. Presumably the uptake of rapid manufacturing would increase sales of both machines and materials thus decreasing costs. While machine and material costs for LMT's remain comparatively high it will be important to identify products which may benefit from Rapid Manufacturing as these may pave the way for more widespread use; this is discussed below.

\section{Issues which will affect the growth of Rapid Manufacturing}


The cost analysis described above has set the scene by showing how the prospect of using LMT's for the production of parts in medium to high volumes may be of immediate interest to manufacturing organisations. This section concentrates on the issues that will affect the uses for LMT's as manufacturing processes and is based on the discussions held on the internet conference. The discussions highlighted three major areas of interest as being:

- Material properties from LMT’s

- Quality control using LMTs’

- Identification of suitable products to be produced by LMT’s

\section{Material properties}

Material properties for parts made by current LMTs seldom match those of their counterparts produced by traditional processes such as injection moulding however significant improvements have been made and should continue to do so. In may cases moulded parts are made from materials which have been developed to have material properties such as high impact resistance, Young's modulus etc. It should be noted however, that moulded materials have had over a century of development whereas layer manufactured materials have had one tenth of this. An example of the time taken to develop materials is outlined below:

The injection moulding process yielded only one useful plastic moulding material (cellulose acetate) some 20 years after it had first been attempted. In comparison, the Selective Laser Sintering (SLS) process has evolved over around 10 years and now may be used to produce parts in numerous materials including plastics, metals, ceramics and composites. 
This view suggests that in future material made by LMT's may well match or exceed their moulded counterparts. This will be even more likely when LMT's are recognised as production processes and materials are developed with end use in mind.

A major barrier may be that of replacing moulded parts, which have a track record of success, with layer manufactured versions which have not been used so extensively; there may be a significant delay (perhaps 2-3 years (5)) between the development of materials and market confidence in their use.

\section{Quality control}

Current RP machines are intended (and designed) to make a variety of parts with various different geometries however this is not true for say machining process (lathes for circular profiles, EDM machines for deep sections and milling machines for other geometries). The Align Technologies example shows how a standard RP machine may be tweaked to generate significant returns when a certain geometry type is catered for. The benefits shown by Align in terms of productivity will also have some bearing on repeatability and part quality produced by dedicated LMT's for production; for example an FDM machine used to produce parts with intricate features could have a suitably sized nozzle attached so that the smallest features could always be produced accurately.

Another area for concern regarding quality control is the raw material used; at present unused material in processes such as SLS or 3D Printing are often simply scooped back into the feed tray. A layer-manufacturing machine working in production may need an automated process for mixing, cleaning and re-feeding unused material (6). 
Rapid Manufacturing also allows for distributed manufacture, so a part to be sold and used in China may be made in China, likewise the same product may be made in the UK, USA or Australia as required. Maintaining repeatability between parts, which are made on different machines often with different working practices, and even different weather conditions may prove difficult. The use of closed loop machine control to improve repeatability has been suggested (6). This would entail measuring a Rapid Manufactured, part for example for a critical geometry or material response, and feeding the results back into the LMT software which would automatically change processing parameters in order to get closer to target values.

\section{Identifying suitable products.}

The role of high machine and material costs in the cost analysis showed how the identification of products which have most to gain from Rapid Manufacturing need to be found in order that its growth occurs.

It was suggested that looking at products where capital equipment, operating and maintenance costs are all very high and volumes are low could help to identify good target applications (7). When considering the price per part, small production volumes nearly always incur large capital, operating and maintenance costs so looking at low volumes alone may be sufficient.

Table II showed how small parts appear to be more suited to Rapid Manufacturing, this point was mentioned in the internet conference (5) with the suggestion that larger parts are ignored for rapid manufacturing purposes. Other than for very low production volumes, the material cost and machine speed of current processes renders Rapid Manufacturing inappropriate for 
large parts, this will probably continue to be the case unless machine speed and material costs are significantly improved.

It should also be noted that all the parts used in the cost analysis were selected as they had high geometric complexity which is typical for injection moulding. This high complexity increases tooling costs and therefor increases the likelihood that Rapid Manufacturing may be a viable route. The importance of geometric complexity may be seen in software used to estimate mould costs such as MoldCoster (8), which increases tool cost significantly with geometry such as undercuts.

\section{Conclusions}

The current examples of Rapid Manufacturing coupled with the cost analysis indicate that the use of LMT's to manufacture products in medium to high volumes is a credible idea. Reductions in machine and material cost coupled with increases in machine throughput and material proper will help Rapid Manufacturing to grow. The cost analysis combined with opinions generated in the internet conference suggest that small parts with high geometric complexity to be made in relatively small volumes are the most suitable candidates for Rapid Manufacturing.

\section{References}

1. Selective Laser Sintered parts used directly in spacecraft production, Rapid Prototyping Report, Vol 9, No. 11, November 1999

2. http://www.dtm-corp.com/applications/nasa.html 
3. http://www.3dsystems.com/index_nav.asp?nav=newsevents\&subnav=news\&content= newsevents/newsreleases/pr-001122.asp

4. Rapid manufacturing - Using Additive Manufacturing Processes for Production, Time Compression Technologies Magazine (Europe), Vol 8, Issue 4, pp 53-58, August 2000

5. http://www.rapid-discussion.com/discus2/messages/board-topics.html RP for Direct Manufacture Comments by Steve Windsor

6. http://www.rapid-discussion.com/discus2/messages/board-topics.html RP for Direct Manufacture Comments by Mike Ervin

7. http://www.rapid-discussion.com/discus2/messages/board-topics.html RP for Direct Manufacture Comments by dawn White

8. http://www.iplas.com/MOLDCOSTER.htm

\section{$\underline{\text { Authors Details }}$}

Dr Neil Hopkinson

Rapid Manufacturing Research Group

Department of Mechanical \& Manufacturing Eng

De Montfort University

Queens Building, The Gateway, 
Leicester,

LE1 9BH,

UK.

Tel +44 1162551551 x8064

Fax +44 116257705

Prof. P. M. Dickens

Dept. of Engineering \& Technology

De Montfort University

The Gateway

Leicester

England LE1 9BH

Tel: +44 (0)116 2577689

Fax: +44 (0)116 2577025

Mobile: +44 (0)7768 827039

Email:pdickens@dmu.ac.uk 